\title{
Adsorption of atrazine from water in metal-organic framework materials
}

\author{
Isil Akpinar and A. Ozgur Yazaydin* \\ Department of Chemical Engineering, University College London, London WC1E 7JE, United \\ Kingdom
}

\begin{abstract}
The adsorptive removal of atrazine, an agricultural herbicide, from water by three water stable MOFs; ZIF-8, UiO-66 and UiO-67 and a commercial activated carbon, F400, was investigated. UiO-67, ZIF-8 and F400 were found to remove up to $98 \%$ of the atrazine from water, whereas UiO-66 is found to be ineffective. In an exceptional performance compared to the other adsorbents considered in our study, UiO-67 removed 98\% of atrazine from water within only 2 minutes, whereas ZIF-8 and F400 took over 40 and 50 minutes, respectively, to remove the same amount of atrazine. Upon regeneration of UiO-67, minimal loss of adsorption capacity was observed, affirming its effective use for atrazine removal from water.
\end{abstract}




\section{INTRODUCTION}

Contamination of surface and ground water with herbicides is a major concern due to the hazards these chemicals pose to the environment and humans. ${ }^{1-3}$ Atrazine, 6-chloro-N-ethyl-N'-(1methylethyl)-1,3,5-triazine-2,4-diamine, is one of the most commonly used herbicides in agriculture and is listed as an endocrine disrupting compound by the US Environmental Protection Agency. ${ }^{4}$ As a result of extensive use, atrazine has been found in drinking water supplies and groundwater. ${ }^{5-6}$ Therefore, the removal of atrazine from environmental water has become of interest.

The removal of atrazine from drinking water is known to be challenging and difficult. ${ }^{7}$ Several conventional treatment techniques have been used, such as coagulation/flocculation, filtration and chlorination. While these conventional techniques do not effectively remove atrazine, ${ }^{8-9}$ advanced removal technologies; such as ozone-based oxidation, ${ }^{9-10}$ reverse osmosis, nanofiltration and adsorption ${ }^{11}$ are found to be promising. In particular, adsorption based removal of atrazine from water is attractive due to the ease of operation, low initial cost and the by-product-free removal process. ${ }^{12}$ Activated carbon, ${ }^{13}$ surface modified activated carbon, ${ }^{14}$ organo-zeolites, ${ }^{5}$ clay minerals modified with a cationic surfactant, ${ }^{15}$ carbon nanotubes, ${ }^{16}$ surface oxidized multiwalled carbon nanotubes, ${ }^{17-18}$ activated carbon/iron oxide composites, ${ }^{1}$ zeolite-rich tuffs ${ }^{19}$ and banana peel based sorbent ${ }^{20}$ have been studied for the adsorptive removal of atrazine so far.

Metal-organic frameworks (MOFs) are hybrid inorganic-organic crystalline materials built by the self-assembly of inorganic metal ions and organic ligands through coordination bonds. ${ }^{21}$ Due to their intriguing properties, such as tunable pore size and shape, versatile chemical 
functionality, high surface area and porosity and the abundance of active sites, MOFs are considered as promising adsorbents for liquid phase separation and purification applications. ${ }^{22-26}$ Exploring novel adsorbents for efficient removal of atrazine is still of great significance. To the best of our knowledge the adsorptive removal of atrazine from aqueous solutions using MOFs has not been investigated. In this study, we considered three MOFs for the removal of atrazine; $\mathrm{ZIF}-8,{ }^{27} \mathrm{UiO}-66$ and UiO-67, ${ }^{28}$ due to their excellent water, chemical and thermal stabilities. Zeolitic imidazolate framework-8 (ZIF-8) is formed by zinc metal ions linked by 2methylimidazole ligands and has $11.6 \AA$ pores accessible through $3.4 \AA$ apertures. UiO-66 and UiO-67 are isostructural Zr-based MOFs. UiO-66 is formed by hexanuclear zirconium $\left(\mathrm{Zr}_{6} \mathrm{O}_{4}(\mathrm{OH})_{4}\right)$ clusters and 1,4 benzene-dicarboxylate (BDC) linker ${ }^{28-29}$ which possess $11 \AA$ octahedral pores and $8 \AA$ tetrahedral pores which are accessed by apertures of 5 and $7 \AA$, respectively. ${ }^{29-30}$ UiO-67 consists of 4,4' biphenyl-dicarboxylate (BPDC) linker instead of BDC, and therefore presents larger pores compared to UiO-66 (i.e. $12 \AA$ tetrahedral and $16 \AA$ octahedral pores). ${ }^{31}$ The chemical structure and physicochemical properties of atrazine as well as structural models of ZIF-8, UiO-66 and UiO-67 are given in Figure 1 and Table 1. For comparison purposes, we also included a commercially available activated carbon, Filtrasorb400 (F400), in our study. 

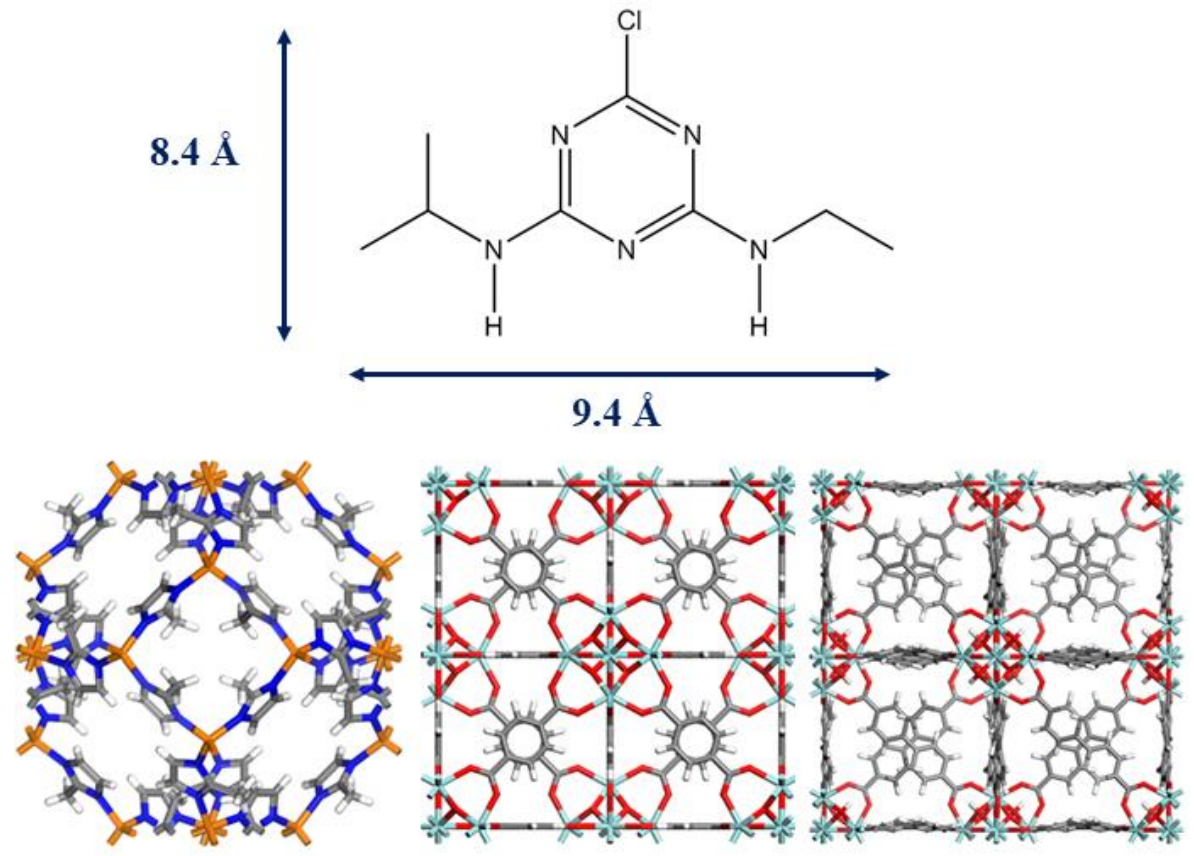

\section{$11.6 \AA$}

$8 \AA$ and $11 \AA$

$12 \AA$ and $16 \AA$

Figure 1 Chemical structure of atrazine (top) and the structural models of ZIF-8, UiO-66 and UiO-67 (bottom, from left to right) showing their pore sizes. Color code: carbon (black), oxygen (red), nitrogen (blue), zinc (orange) and zirconium (cyan).

Table 1 Physicochemical properties of atrazine

\begin{tabular}{|c|c|c|c|c|}
\hline $\begin{array}{c}\text { Chemical } \\
\text { Formula }\end{array}$ & $\begin{array}{c}\text { Solubility in water } \\
(\mathrm{mg} / \mathrm{L})^{7,32}\end{array}$ & $\operatorname{LogK}_{\mathrm{ow}}{ }^{33}$ & $\mathrm{pK}_{\mathrm{a}}^{33}$ & $\begin{array}{c}\text { Molecular } \\
\text { Dimensions* }\end{array}$ \\
\hline $\mathrm{C}_{8} \mathrm{H}_{14} \mathrm{ClN}_{5}$ & 33 & 2.67 & 1.85 & $9.4 \times 8.4 \times 3.2 \AA$ \\
\hline
\end{tabular}

*as measured with ChemBioOffice 2014-Chembiodraw3D (Cambridge Soft Corporation)

\section{MATERIALS AND METHODS}

\subsection{Chemicals}

Zinc nitrate hexahydrate $\left(\mathrm{Zn}\left(\mathrm{NO}_{3}\right)_{2} .6 \mathrm{H}_{2} \mathrm{O}, 98 \%\right.$, Sigma Aldrich), 2-methylimidazole $\left(\mathrm{C}_{4} \mathrm{H}_{6} \mathrm{~N}_{2}\right.$, Sigma Aldrich), zirconium chloride $\left(\mathrm{ZrCl}_{4}, \mathrm{Merck}\right)$, terephthalic acid (BDC for synthesis, $\mathrm{C}_{6} \mathrm{H}_{4}-$ 
1,4-( $\left.\mathrm{CO}_{2} \mathrm{H}\right)_{2}$, VWR International), 4,4' biphenyl dicarboxylic acid (BPDC, Sigma Aldrich), sodium hydroxide solution ( $\mathrm{NaOH}$, Sigma Aldrich), atrazine (Cayman Chemical, $\geq 98$ ), N,N dimethylformamide (DMF, Sigma Aldrich, SIAL, >99.8), methanol (HPLC Grade, Fisher Scientific), absolute ethanol (Merck), hydrochloric acid (HCl, 36.5-38 \%, Sigma Aldrich) and sulphuric acid $\left(\mathrm{H}_{2} \mathrm{SO}_{4}\right.$, Sigma Aldrich, 95-98 \%) were purchased and used as received. F400 was supplied by Chemviron Calgon.

\subsection{Syntheses procedures of ZIF-8, UiO-66 and UiO-67}

ZIF-8 was prepared based on the procedure reported by $\mathrm{Fu}$ et al. ${ }^{34} 3.0 \mathrm{~g}$ of zinc nitrate hexahydrate was dissolved in $60 \mathrm{~mL}$ of methanol and $8.3 \mathrm{~g}$ of 2-methylimidazole was dissolved in $60 \mathrm{~mL}$ of methanol separately. The two solutions were then mixed together in a $250-\mathrm{mL}$ glass jar. The mixture was then sonicated for 15 minutes at $70^{\circ} \mathrm{C}$ and a milky white solution was obtained. The ZIF-8 powder was collected by washing with methanol by centrifugation (Thermo Scientific, Sorvall-Legend X1R) at $10000 \mathrm{rpm}$ for 10 minutes several times and dried at $100^{\circ} \mathrm{C}$ overnight under vacuum (Heraeus Instruments Vacutherm, VT6025 Vacuum Oven and PumpPC3001 VarioPro, Vario).

UiO-66 and UiO-67 were prepared according to the procedures reported by Katz et al. ${ }^{35-36}$ For UiO-66, $125 \mathrm{mg}$ of zirconium chloride, $5 \mathrm{~mL}$ of $\mathrm{DMF}$ and $1 \mathrm{~mL}$ of concentrated $\mathrm{HCl}$ were placed in a glass bottle and ultrasonicated for 20 minutes until completely dissolved. $123 \mathrm{mg}$ of terephthalic acid and $10 \mathrm{~mL}$ of DMF were then added to the mixture and sonicated for further 20 minutes. The consequent mixture was then placed in an oven at $80{ }^{\circ} \mathrm{C}$ overnight. The resulting white solid was separated from the mother liquor and washed with DMF 2 times $(2 \times 30 \mathrm{~mL})$ followed by washing with ethanol 3 times by centrifugation. Finally, the sample was dried in a vacuum oven at $90{ }^{\circ} \mathrm{C}$ overnight to obtain UiO-66 crystals. 
For UiO-67, $335 \mathrm{mg}$ of zirconium chloride was dissolved in $25 \mathrm{~mL}$ of DMF with $2.5 \mathrm{~mL} \mathrm{HCl}$ for 20 minutes ultrasonication. $450 \mathrm{mg} \mathrm{4,4'} \mathrm{biphenyl} \mathrm{dicarboxylic} \mathrm{acid} \mathrm{and} \mathrm{50mL} \mathrm{of} \mathrm{DMF} \mathrm{were}$ then added to the solution and sonicated for 20 minutes. The vials were heated at $80{ }^{\circ} \mathrm{C}$ in an oven for $24 \mathrm{~h}$. After cooling, the white solid was washed twice with DMF followed by 3 times with acetone by centrifugation. The solid was finally dried in a vacuum oven at $90{ }^{\circ} \mathrm{C}$ overnight to give UiO-67 as a white powder.

\subsection{Characterization of the adsorbents}

The crystallinity of ZIF-8, UiO-66 and UiO-67 was confirmed by powder X-ray diffraction (PXRD). PXRD patterns of the materials were obtained using a Bruker-AXS D4 machine with $\mathrm{Cu} \mathrm{K} \alpha$ radiation $(\lambda=1.5418 \AA)$ in transmission mode and in the range of $5^{\circ} \leq 2 \theta \leq 50^{\circ}$ with a step size/width of $0.05^{\circ}$ and a scan rate of $2 \mathrm{~s} /$ step. $\mathrm{N}_{2}$ adsorption measurements of ZIF-8, F400 and UiO-67 were conducted on a Micromeritics Tristar porosity analyser and that of UiO-66 was performed on a Quantachrome Autosorb IQ MP Physisorption Analyser at $77 \mathrm{~K}$ to assess the BET surface area, total pore volume and the pore size distribution. $70 \mathrm{mg}$ of each sample were weighed and then degassed at $150{ }^{\circ} \mathrm{C}$ for ZIF-8, UiO-67 and $\mathrm{F} 400$ overnight and at $120{ }^{\circ} \mathrm{C}$ for UiO-66 for 16 hours under vacuum prior to analysis.

\subsection{Adsorption Experiments}

A stock solution of atrazine was prepared by dissolving $25 \mathrm{mg}$ of atrazine in $1 \mathrm{~L}$ ultrapure water

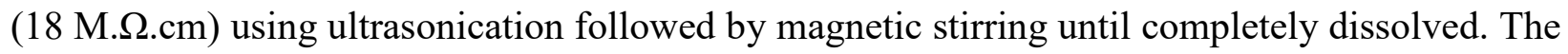
solutions of desired concentrations for calibration standards and batch adsorption experiments were obtained by diluting the atrazine stock solution with ultrapure water. A calibrated micropipette was used for this purpose in order to ensure accuracy. All adsorption experiments were carried out at $25^{\circ} \mathrm{C}$. 
To study the efficiency of the adsorbents for the removal of atrazine, 5 to $150 \mathrm{mg}$ of each adsorbent was added to $25 \mathrm{~mL}$ of atrazine solution with an initial concentration of $25 \mathrm{mg} \mathrm{L}^{-1}$. The glass vials with these solutions and adsorbents were placed in an incubator shaker (SCQuip) and the solutions were shaken at $250 \mathrm{rpm}$ for 24 hours at $25^{\circ} \mathrm{C}$. Control experiments were also carried out without adding adsorbents. All experiments were duplicated, and the mean values are reported in this study. After 24 hours, the control solution and samples were filtered through a syringe filter (cellulose membrane, $0.2 \mu \mathrm{m}$, Sartorius Minisart Syringe Filter). The atrazine equilibrium concentrations were measured using a HPLC Shimadzu LC2010HT system which consists of a binary pump, a column thermostat, an auto sampler and a UV-Vis detector. The reverse phase HPLC column, C18 (Hichrom, ACE $5 \mathrm{C} 18,150 \mathrm{~mm}$ x $4.6 \mathrm{~mm}, 5 \mu \mathrm{m}$ particle) was used with a water/methanol mobile phase $(45: 55 \% \mathrm{v} / \mathrm{v})$ at a flow rate of $1 \mathrm{~mL} / \mathrm{min}$. The detector was set at $223 \mathrm{~nm}$ wavelength and the column temperature was set to $25^{\circ} \mathrm{C}$.

Atrazine concentrations in the stock solution and in the filtrate, were calculated by comparing the obtained peak area corresponding to atrazine with respect to the calibration standard. The efficiency of atrazine removal (in \%) by the adsorbent was determined by the following equation:

$$
\text { Removal (\%) }=\frac{C_{0}-C_{e}}{C_{e}} \times 100
$$

where $\mathrm{C}_{0}\left(\mathrm{mg} \mathrm{L}^{-1}\right)$ is the initial concentration and $\mathrm{C}_{\mathrm{e}}\left(\mathrm{mg} \mathrm{L}^{-1}\right)$ is the residual concentration of atrazine in the stock solution and filtrate, respectively.

Adsorption isotherms of atrazine in $\mathrm{ZIF}-8$, UiO-67 and F400 were measured. For this purpose, $15 \mathrm{mg}$ of ZIF-8, F400 and UiO-67 were weighed into $25 \mathrm{~mL}$ atrazine solutions with initial concentrations between 2 and $25 \mathrm{mg} \mathrm{L}^{-1}$ in glass vials. Samples containing adsorbent and the control sample ( $25 \mathrm{~mL}$ of atrazine solution without adsorbent) were then shaken at $250 \mathrm{rpm}$ and 
$25^{\circ} \mathrm{C}$ for $24 \mathrm{~h}$ in the incubator shaker. Then the samples and control sample were filtered off with a syringe filter. HPLC was used to measure the initial and residual atrazine concentrations in water. Finally, the amount of adsorbed atrazine was calculated by using the mass-balance equation. ${ }^{37}$

$$
Q_{e}=\frac{\left(C_{0}-C_{e}\right) \times V}{m}
$$

where $\mathrm{Q}_{\mathrm{e}}\left(\mathrm{mg} \mathrm{g}^{-1}\right)$ is the amount adsorbed per unit mass of adsorbent at equilibrium, $\mathrm{C}_{0}$ and $\mathrm{C}_{\mathrm{e}}$ $\left(m g \mathrm{~L}^{-1}\right.$ ) are the initial and the equilibrium concentrations of atrazine, respectively, $\mathrm{V}(\mathrm{L})$ is the volume of the atrazine solution and $\mathrm{m}(\mathrm{g})$ is the weight of the adsorbent used.

Freundlich, ${ }^{38}$ Langmuir ${ }^{39}$ and Langmuir-Freundlich ${ }^{40-41}$ adsorption models were considered to describe the isotherms, which are given in (3), (4) and (5), respectively,

$$
\begin{aligned}
& \ln Q_{e}=\ln K_{f}+\left(\frac{1}{N}\right) \ln C_{e} \\
& \frac{1}{Q e}=\left(\frac{1}{Q_{m} \times K_{L}}\right) \frac{1}{C_{e}}+\frac{1}{Q_{m}} \\
& Q_{e}=\frac{Q_{m} \times C_{e}{ }^{N} \times K_{L}}{1+K_{L} \times C_{e}}
\end{aligned}
$$

where $\mathrm{K}_{\mathrm{f}}\left(\left(\mathrm{mg} \mathrm{g}^{-1}\right)\left(\mathrm{L} \mathrm{mg}^{-1}\right)^{1 / \mathrm{N}}\right)$ is the Freundlich adsorption constant, $\mathrm{N}$ is the degree of nonlinearity and adsorption intensity of the adsorbents, $\mathrm{Q}_{\mathrm{m}}\left(\mathrm{mg} \mathrm{g}^{-1}\right)$ is the Langmuir maximum adsorption capacity and $\mathrm{K}_{\mathrm{L}}\left(\mathrm{L} \mathrm{mg}^{-1}\right)$ is the Langmuir adsorption constant.

To study the adsorption kinetics of atrazine, $150 \mathrm{mg}$ of ZIF-8, UiO-67 and F400 were separately weighed into glass vials which contained $25 \mathrm{~mL}$ of atrazine solution at an initial concentration of $25 \mathrm{mg} \mathrm{L}^{-1}$. Afterwards, the glass vials were placed in the incubator shaker and were shaken at $250 \mathrm{rpm}$ at $25^{\circ} \mathrm{C}$. Samples were collected at frequent time intervals ( $2 \mathrm{~min}, 5 \mathrm{~min}$, $10 \mathrm{~min}, 15 \mathrm{~min}, 30 \mathrm{~min}, 45 \mathrm{~min}, 60 \mathrm{~min}, 90 \mathrm{~min}$ and $120 \mathrm{~min}$ ), filtered through a syringe filter and placed in HPLC vials to be analysed by HPLC to determine the concentration of the atrazine 
at any time in the solution. The amount of adsorbed atrazine on the adsorbents was calculated by using the following mass-balance relationship.

$$
Q_{t}=\frac{\left(C_{0}-C_{t}\right) \times V}{m}
$$

where $\mathrm{Q}_{\mathrm{t}}\left(\mathrm{mg} \mathrm{g}^{-1}\right)$ is the amount adsorbed per unit mass of adsorbent at time $\mathrm{t}, \mathrm{C}_{0}\left(\mathrm{mg} \mathrm{L}^{-1}\right)$ is initial liquid-phase concentration of atrazine at time $=0, C_{t}\left(\mathrm{mg} \mathrm{L}^{-1}\right)$ is the residual concentration of atrazine at time $t$.

To explore the adsorption kinetics in UiO-67 and ZIF-8 (kinetics of UiO-66 are omitted owing to its poor removal efficiency) the pseudo first order ${ }^{42}$ and pseudo-second order kinetic models ${ }^{43}$ are calculated by Eqs (7) and (8), respectively, and are represented in linearized form as follows:

$$
\begin{aligned}
& \ln \left(Q_{e}-Q_{t}\right)=\ln \left(Q_{e}\right)-k_{1} \times t \\
& \frac{t}{Q_{t}}=\frac{1}{k_{2} \times Q_{e}{ }^{2}}+\frac{t}{Q_{e}}
\end{aligned}
$$

where $\mathrm{Q}_{\mathrm{t}}\left(\mathrm{mg} \mathrm{g}^{-1}\right)$ and $\mathrm{Q}_{\mathrm{e}}\left(\mathrm{mg} \mathrm{g}^{-1}\right)$ are the amounts of atrazine adsorbed at time $\mathrm{t}(\mathrm{min})$ and at equilibrium, respectively; $\mathrm{k}_{1}\left(\mathrm{~min}^{-1}\right)$ is the pseudo first order rate constant and $\mathrm{k}_{2}\left(\mathrm{~g} \mathrm{mg}^{-1} \mathrm{~min}^{-1}\right)$ is the pseudo second order rate constant. The $\mathrm{pH}$ of the solution was adjusted using $0.01 \mathrm{M}$ sulphuric acid or $0.01 \mathrm{M}$ sodium hydroxide solution in order to study the effect of $\mathrm{pH}$ on adsorption.

\section{RESULTS AND DISCUSSION}

\subsection{Characterization of adsorbents}

The phase purity of the synthesized materials and the crystalline stability of UiO-67 after atrazine adsorption uptake were characterised by PXRD. As shown in Figure S1, the simulated and experimental PXRD patterns of UiO-67, UiO-66 and ZIF-8 are in good agreement, which confirms their successful preparation. 
$\mathrm{N}_{2}$ adsorption isotherms at $77 \mathrm{~K}$ for UiO-67, UiO-66, ZIF-8 and F400 are shown in Figure S2. BET surface areas and pore volumes are given in Table 2, and pore size distributions are presented in Figure 2. UiO-67 has the highest surface area and pore volume among the four adsorbents, followed by ZIF-8, UiO-66 and F400. Pore size distributions, which were determined by density functional theory (DFT) analysis ${ }^{44-45}$, reveal that UiO-67 possesses both micropores and mesopores (i.e. > $20 \AA$, due to defects), whereas ZIF-8 and UiO-66 possess only micropores.

Table 2. Surface and pore size characteristics of ZIF-8, UiO-66 and activated carbon (F400).

\begin{tabular}{|c|c|c|c|}
\hline Materials & $\begin{array}{c}\text { Surface Area, } \\
\mathbf{m}^{\mathbf{2}} / \mathbf{g}^{\mathbf{a}}\end{array}$ & $\begin{array}{c}\text { Total Pore } \\
\text { Volume } \mathbf{\mathbf { c m } ^ { 3 }} / \mathbf{g}^{\mathbf{b}}\end{array}$ & $\begin{array}{c}\text { Micropore Volume } \\
\mathbf{c m}^{\mathbf{3}} \mathbf{g}\end{array}$ \\
\hline ZIF-8 & 1875 & 0.714 & 0.660 \\
\hline UiO-66 & 1640 & 0.656 & 0.621 \\
\hline UiO-67 & 2345 & 1.249 & 0.930 \\
\hline F400 & 1135 & 0.584 & 0.241 \\
\hline
\end{tabular}

${ }^{\mathrm{a}}$ Calculated within $0.005-0.20$ relative pressure $\left(\mathrm{P} / \mathrm{P}_{\mathrm{o}}\right)$ range,

${ }^{\mathrm{b}}$ Estimated at a relative pressure of 0.95
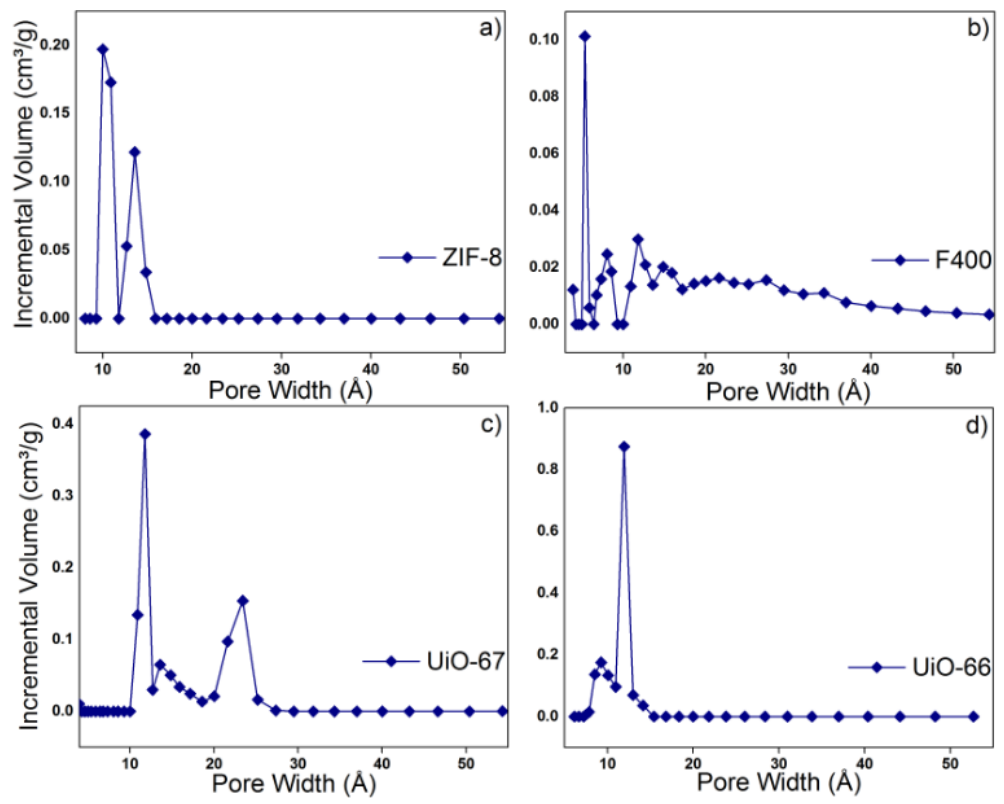

Figure 2. Pore size distributions of a) ZIF-8, b) F400, c) UiO-67 and d) UiO-66.

\subsection{Effect of Adsorbent Amount on the Removal of Atrazine}


Figure 3 shows the removal efficiency of atrazine with increasing amounts of adsorbent amount in a $25 \mathrm{mg} \mathrm{L}^{-1}$ atrazine solution. At $2.4 \mathrm{mg} \mathrm{mL}^{-1}$ adsorbent concentration, both UiO-67 and $\mathrm{F} 400$ remove more than $90 \%$ of atrazine; whereas, ZIF-8 removes $60 \%$ of the atrazine and UiO-66 removes $20 \%$ of the atrazine present in the solution. At $6 \mathrm{mg} \mathrm{mL}^{-1}$ adsorbent concentration, all adsorbents except UiO-66 removes $98 \%$ of the atrazine.

The effectiveness of UiO-67 compared to UiO-66 in removing atrazine may be attributed to the presence of larger pores in UiO-67 (Figure 2c and Table 2). Furthermore, the pore apertures of UiO-66 may not be large enough to allow atrazine to access its pores. On the other hand, although atrazine is not expected to enter the pores of ZIF-8 due to its narrow pore aperture, ZIF8 stills effectively removes almost all atrazine from water. This may be due to the hydrophobicity of ZIF- $8^{46}$ which blocks water adsorption in significant amounts and promotes adsorption of the hydrophobic atrazine molecules possibly on the external surface. In contrast, the hydrophilic character of UiO-66 makes it ineffective at removing of atrazine from water even by surface interaction. ${ }^{46-47}$

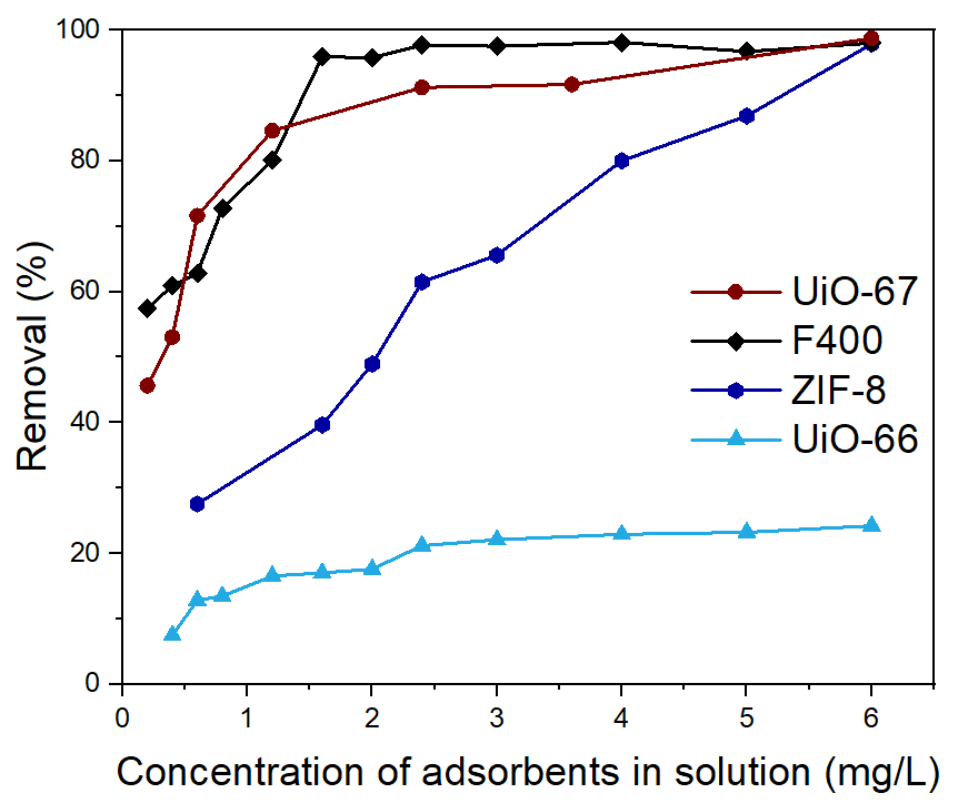


Figure 3. The effect of adsorbent amount on the removal efficiency of atrazine from water (atrazine concentration, $25 \mathrm{mg} \mathrm{L}^{-1}$ ).

\subsection{Kinetics of Atrazine Adsorption}

Adsorption of atrazine as a function of time was measured in ZIF-8, UiO-67 and F400 at an adsorbent concentration of $6 \mathrm{mg} \mathrm{mL} \mathrm{mL}^{-1}$ (UiO-66 was not considered due to its poor removal efficiency). At this concentration, these three adsorbents removed $98 \%$ of atrazine from the solution (Figure 3). Figure 4 shows the percentage removal efficiency of atrazine as a function of time. UiO-67 removes atrazine much faster than the other two adsorbents, reaching 98\% removal in just 2 minutes. In contrast, ZIF-8 removes only $46 \%$ of the atrazine in 2 minutes and requires 40 minutes to reach $98 \%$ atrazine removal. The removal kinetics of F400 was even worse with less than $20 \%$ atrazine removal in 2 minutes and requiring 50 minutes to reach $98 \%$ removal rate. This faster kinetics of $\mathrm{UiO}-67$ can be attributed to the higher pore volume and larger pore aperture size of UiO-67 compared to the other adsorbents studied.

The kinetics of atrazine adsorption was analyzed by pseudo first order and pseudo second order models (Figures S3 and S4). The calculated kinetic parameters and correlation coefficients are given in Table S1. Kinetics of atrazine adsorption in UiO-67 and ZIF-8 are well represented by the pseudo second order model (Figures S3a and b). The pseudo second order kinetics indicate possible chemisorption of atrazine in UiO-67 and ZIF-8. ${ }^{48-49}$ On the other hand, kinetic data of atrazine adsorption in F400 was better represented by the pseudo first order model (Figure S3c). 


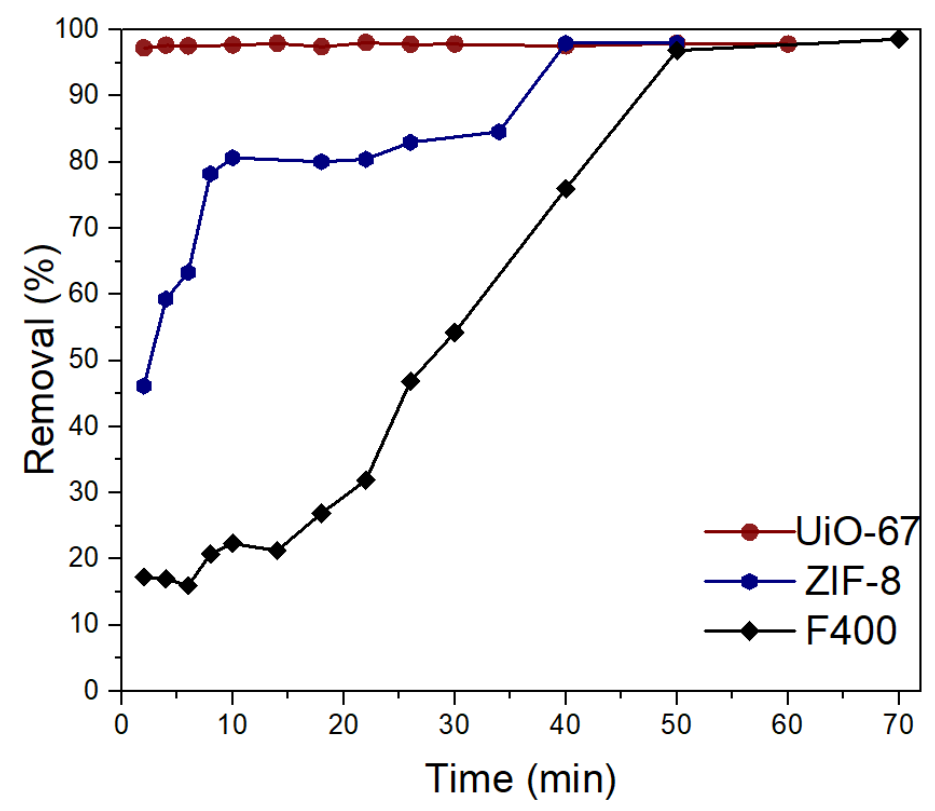

Figure 4. Removal efficiency as a function of time $(150 \mathrm{mg}$ of adsorbents was placed in contact with $25 \mathrm{~mL}$ solution of an initial atrazine concentration of $25 \mathrm{mg} \mathrm{L}^{-1}$ )

\subsection{Adsorption Isotherms of Atrazine}

Adsorption isotherms of atrazine on UiO-67, ZIF-8 and F400 are given in Figure 5. Adsorption equilibrium data were fitted to different isotherm models mentioned in the methodology section. Isotherm model parameters are given in Table S2. Freundlich model gives the best fit for atrazine adsorption in UiO-67, while Langmuir-Freundlich model and Langmuir model give the best fits for ZIF-8 and F400, respectively. Within the atrazine concentration range studied, the gravimetric adsorption capacity of UiO-67 and F400 are about 2.5 times larger than that of ZIF-8 (Figure 5). ZIF-8 has a larger total pore volume than F400; however, it adsorbs much less atrazine. This is because of the narrow pore aperture of ZIF-8 (3.4 $\AA)$ which is small to accommodate atrazine (Table 1); therefore, atrazine is expected to only be being adsorbed on the surface. While F400 and ZIF-8 isotherms reach saturation, it is clear that the UiO-67 isotherm is far from saturation and can adsorb more atrazine owing to its larger pore volume compared to 
F400 and ZIF-8. Due to the low solubility of atrazine in water it is not possible to prepare solutions with higher equilibrium concentrations to probe the maximum atrazine adsorption capacity of UiO-67.

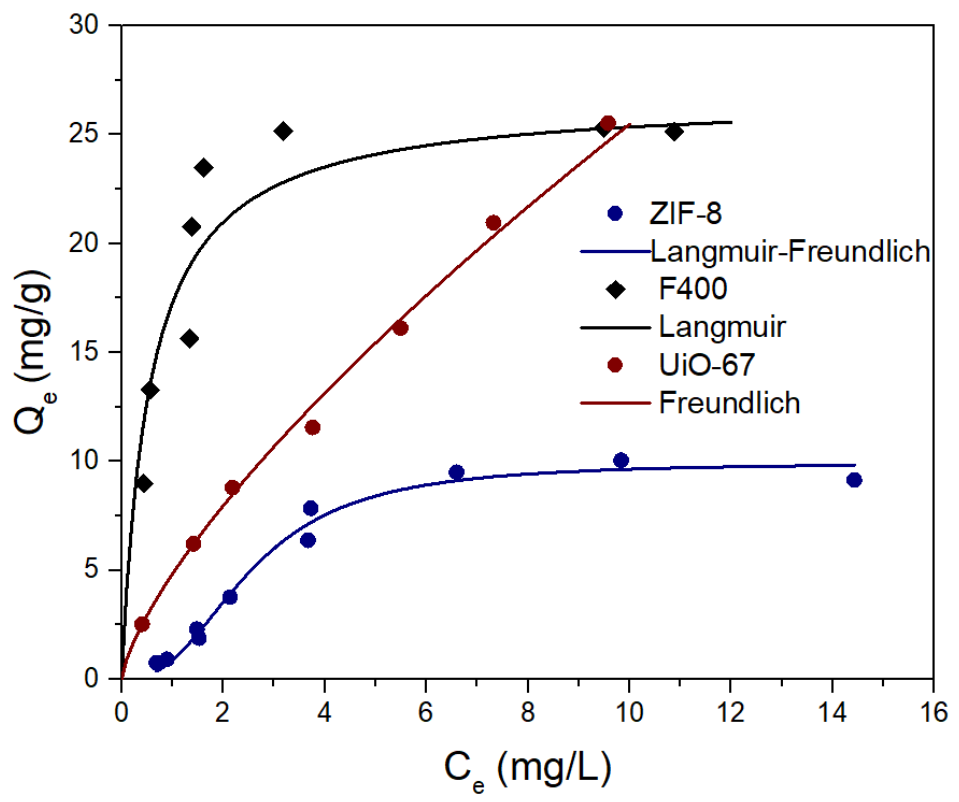

Figure 5. Adsorption isotherm of atrazine in UiO-67, ZIF-8 and F400 and the Langmuir adsorption model fits (lines).

\subsection{Effect of pH on Adsorption of Atrazine}

Table 3 shows the change in the amount of atrazine adsorbed with respect to varying $\mathrm{pH}$ which was obtained by $50 \mathrm{mg}$ of each adsorbent added in to $25 \mathrm{~mL}$ atrazine solution at an initial concentration of $25 \mathrm{mg} \mathrm{L}^{-1}$. It was found that the $\mathrm{pH}$ of the solution does not have a significant effect on atrazine adsorption. This may be due to the fact that the neutral form of atrazine in aqueous solution is dominant over the protonated form. ${ }^{19}$ Overall the insensitivity of the atrazine adsorption to the changes in $\mathrm{pH}$ indicates that the adsorption of atrazine is not governed by electrostatic interaction, but rather hydrophobic interactions and $\pi-\pi$ interactions between the heterocyclic rings of atrazine and the aromatic carbons in the ligands of UiO-67, ZIF-8 and UiO- 
66 and the pore walls of F400. In a similar experimental study of adsorption of micropollutants (including atrazine) in activated carbon, Nam et al. (2014) pointed out that hydrophobic interaction between micropollutants and activated carbon is the dominant mechanism of adsorption for hydrophobic compounds. ${ }^{33}$

Table 3. The effect of $\mathrm{pH}$ on atrazine adsorption by the studied MOFs and F400.

\begin{tabular}{|c|c|c|c|c|}
\hline $\mathbf{p H}$ & \multicolumn{4}{|c|}{ Adsorbed Amount (mg atrazine / g adsorbent) } \\
\hline & ZIF-8 & UiO-66 & UiO-67 & $\mathbf{F 4 0 0}$ \\
\hline 2.8 & 6.27 & 2.69 & 10.45 & 12.28 \\
\hline 4.5 & 6.28 & 2.02 & 11.87 & 12.09 \\
\hline 6.9 (initial pH) & 6.78 & 2.57 & 10.96 & 13.73 \\
\hline 8.9 & 6.19 & 1.71 & 10.04 & 11.53 \\
\hline 9.8 & 6.69 & 1.89 & 10.95 & 12.64 \\
\hline
\end{tabular}

\subsection{Regeneration and Stability of UiO-67}

In order to probe its reusability, UiO-67 was regenerated by washing with copious amount of acetone and stirring at $25^{\circ} \mathrm{C}$ and $250 \mathrm{rpm}$ followed by removal of acetone and heating at $90^{\circ} \mathrm{C}$. Three consecutive atrazine adsorption/desorption cycles were conducted and regenerated UiO-67 showed no significant decrease in adsorption capacity compared to fresh UiO-67. At the end of the third adsorption cycle UiO-67 lost less than $10 \%$ of its original adsorption capacity (Figure 6). This result shows that UiO-67 can be used for the removal of atrazine for several times.

To further investigate the stability of regenerated UiO-67 to the process, $\mathrm{N}_{2}$ adsorptiondesorption isotherms of the UiO-67 regenerated via washing with acetone were measured (Figure 7a). As seen in Figure 7a, the BET surface area was not significantly changed after regeneration in acetone indicating that adsorbed atrazine was successfully desorbed, and the textural 
properties were retained. PXRD pattern observed for atrazine adsorbed UiO-67 upon solvent exchange to acetone from water followed by thermal activation at $90^{\circ} \mathrm{C}$ was identical to the starting materials (Figure 7b). These results suggest that the crystallinity of UiO-67 was conserved under the conditions studied and for comparison, the simulated PXRD pattern of UiO67 was also included. Moreover, SEM images of UiO-67 before adsorption of atrazine and regenerated UiO-67 in acetone after adsorption of atrazine confirms that no morphology change was observed in regenerated UiO-67 (Figure 8). Overall, the regenerated UiO-67`s crystallinity, textural properties and morphology were pleasingly retained without collapsing the structure, which suggests that UiO-67 has potential for atrazine removal from water.

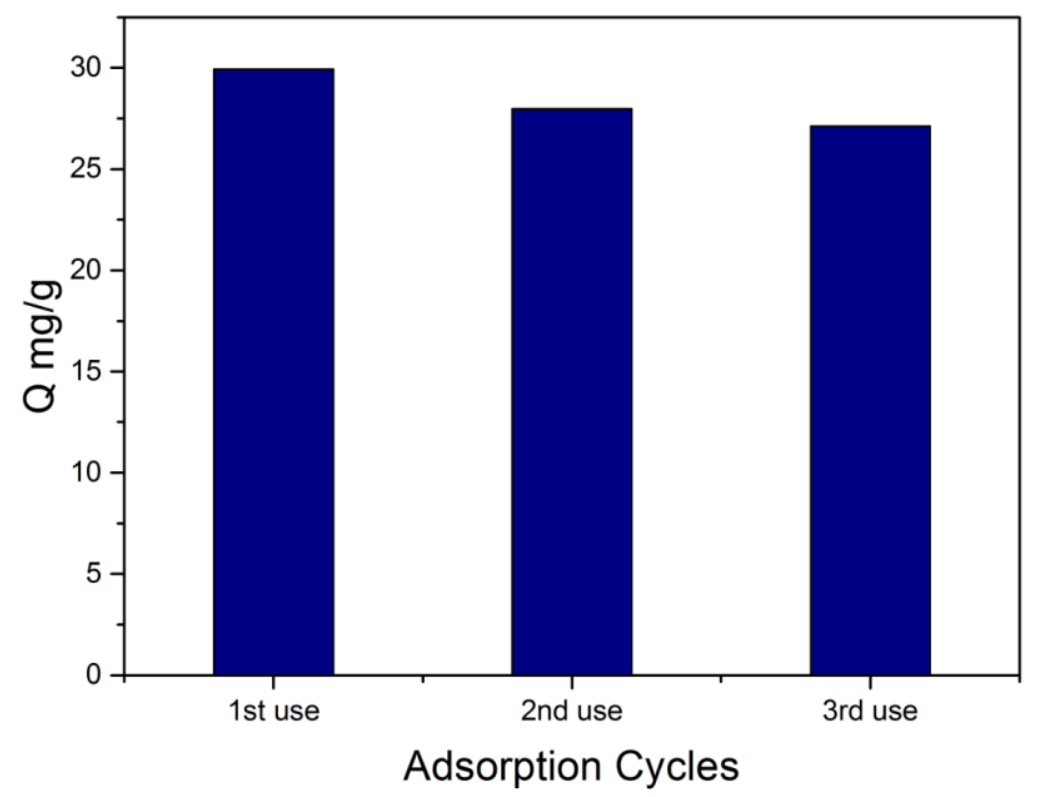

Figure 6. Reusability of UiO-67 for atrazine removal after acetone washing $\left(\mathrm{Ci}=25 \mathrm{mg} \mathrm{L}^{-1}\right.$ and $15 \mathrm{mg}$ adsorbent) 

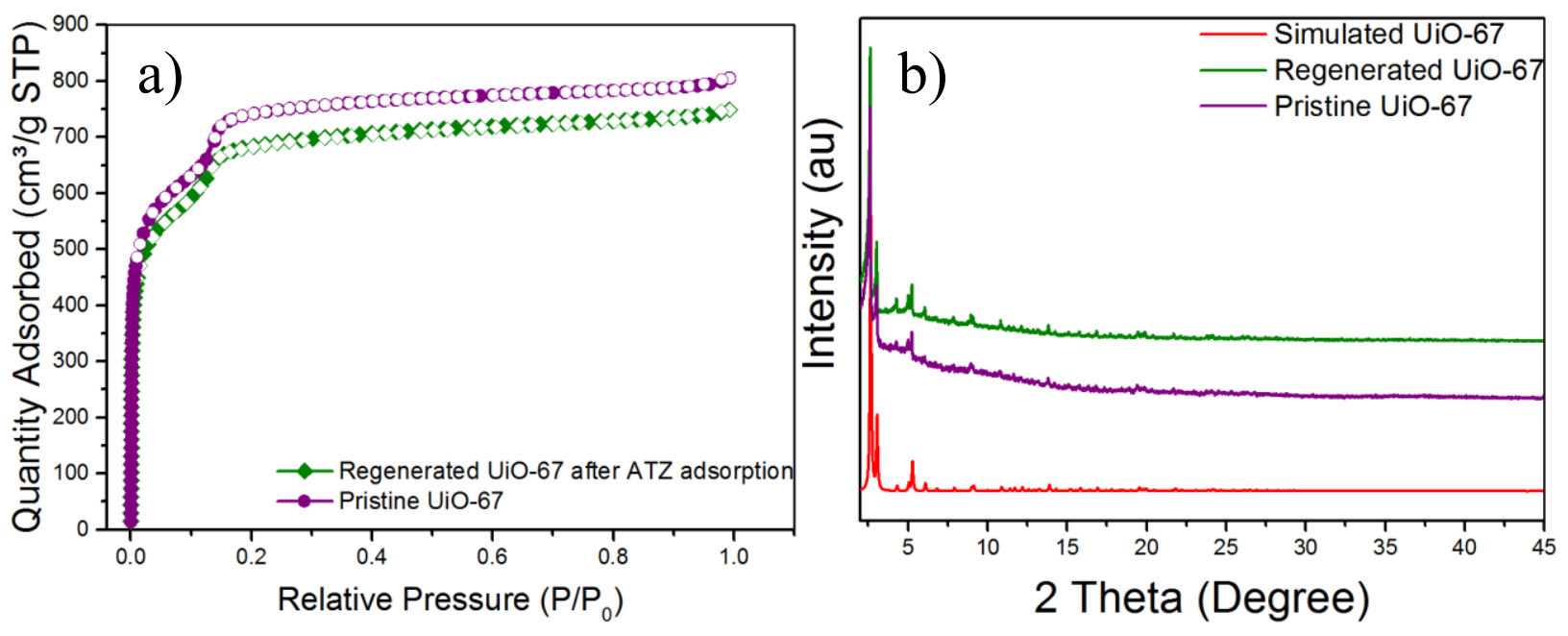

Figure 7. (a) $\mathrm{N}_{2}$ adsorption-desorption isotherms of prepared UiO-67 and regenerated UiO-67 in acetone followed by thermally activated and (b) PXRD patterns of starting UiO-67 before adsorption of atrazine, regenerated after atrazine adsorption and the simulated PXRD pattern of UiO-67 is also included for comparison.

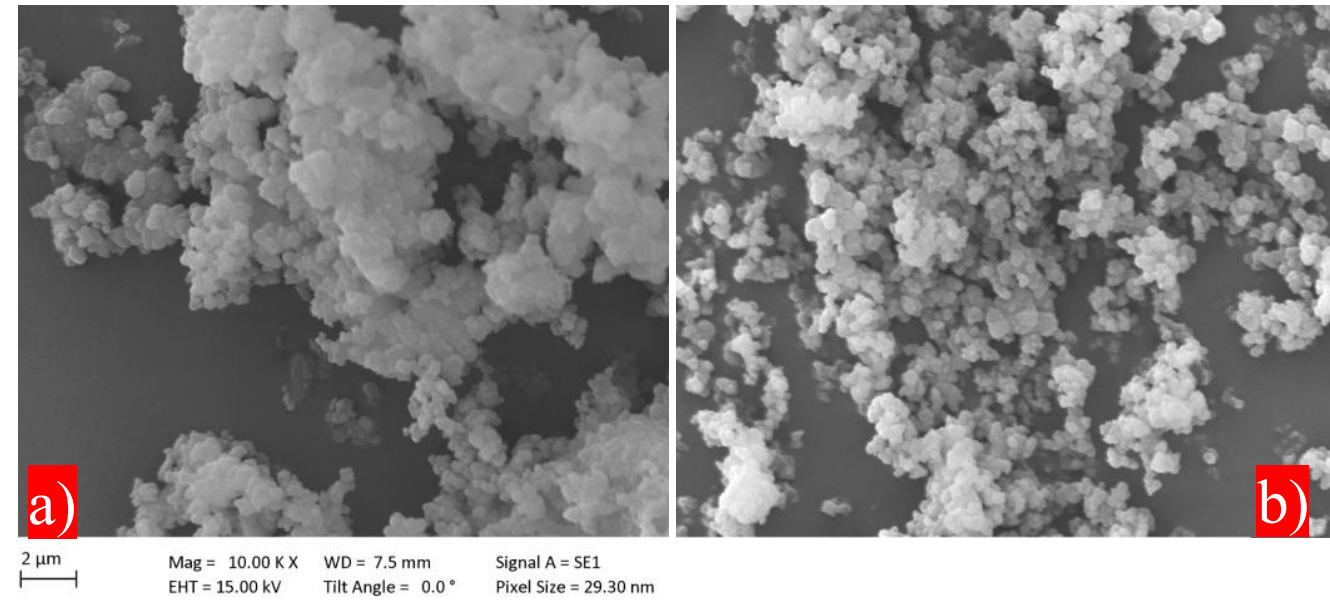

Figure 8. SEM images of (a) pristine UiO-67 before atrazine adsorption and (b) regenerated UiO-67 after atrazine adsorption

\section{CONCLUSIONS}

Three highly porous and water stable MOFs; ZIF-8, UiO-66 and UiO-67, were explored for the adsorption of atrazine from water in comparison with a commercial activated carbon, F400. 
Except UiO-66 all studied adsorbents removed up to $98 \%$ of the atrazine present in water. UiO67 was found to exhibit the fastest rate of atrazine removal, and removed $98 \%$ of atrazine from water in only 2 minutes. In contrast, ZIF-8 took 40 minutes and F400 took 50 minutes to reach the same removal capacity. Moreover, regenerated UiO-67 maintained most of its atrazine adsorption capacity after the third use. Considering its rapid atrazine uptake, comparable adsorption capacity to commercial F400 and its regenerability without significant loss of adsorption capacity, UiO-67 can be considered as a promising adsorbent for the removal of atrazine from water.

\section{ASSOCIATED CONTENT}

\section{Supporting Information}

PXRD patterns of UiO-67, UiO-66 and ZIF-8, $\mathrm{N}_{2}$ adsorption-desorption of isotherms of all four adsorbents, experimental adsorption kinetics of atrazine and their fitting to kinetic models for UiO-67, ZIF-8 and F400, the pseudo first and pseudo second order model parameters and Langmuir-Freundlich, Langmuir and Freundlich adsorption isotherms fitting parameters of atrazine on UiO-67, ZIF-8 and F400 are presented in supporting information.

\section{AUTHOR INFORMATION}

Corresponding Author: *ozgur.yazaydin@ucl.ac.uk

\section{ACKNOWLEDGMENTS}

I.A. acknowledges support by Turkish Ministry of Education for graduate studies.

\section{REFERENCES}

1. Castro, C. S.; Guerreiro, M. C.; Goncalves, M.; Oliveira, L. C.; Anastacio, A. S., Activated Carbon/Iron Oxide Composites for the Removal of Atrazine From Aqueous Medium. J. Hazard. Mater. 2009, 164, 609-614.

2. $\quad$ Zhou, Y.; Zhang, F.; Tang, L.; Zhang, J.; Zeng, G.; Luo, L.; Liu, Y.; Wang, P.; Peng, B.; Liu, X., Simultaneous Removal of Atrazine and Copper Using Polyacrylic Acid-Functionalized 
Magnetic Ordered Mesoporous Carbon from Water: Adsorption Mechanism. Sci. Rep. 2017, 7, 43831.

3. Sanderson, J. T.; Seinen, W.; Giesy, J. P.; van den Berg, M., 2-Chloro-s-Triazine Herbicides Induce Aromatase (CYP19) Activity in H295R Human Adrenocortical Carcinoma Cells: A Novel Mechanism for Estrogenicity? Toxicol. Sci. 2000, 54, 121-127.

4. Environmental Protection Agency, U. S. EDSP: Weight of Evidence Analysis of Potential Interaction with the Estrogen, Androgen or Thyroid Pathyways https://www.epa.gov/endocrine-disruption/endocrine-disruptor-screening-program-tier-1-

screening-determinations-and (accessed 14 November 2016).

5. Lemic, J.; Kovacevic, D.; Tomasevic-Canovic, M.; Kovacevic, D.; Stanic, T.; Pfend, R., Removal of Atrazine, Lindane and Diazinone From Water by Organo-Zeolites. Water Res. 2006, 40, 1079-1085.

6. Chen, C.; Yang, S.; Guo, Y.; Sun, C.; Gu, C.; Xu, B., Photolytic Destruction of Endocrine Disruptor Atrazine in Aqueous Solution Under UV Irradiation: Products and Pathways. J. Hazard. Mater. 2009, 40, 675-684.

7. Streat, M.; Horner, D. J., Adsorption of Highly Soluble Herbicides from Water Using Activated Carbon and Hypercrosslinked Polymers. Process Saf. Environ. Prot. 2000, 78, 363382.

8. Brown, N. W.; Roberts, E. P.; Chasiotis, A.; Cherdron, T.; Sanghrajka, N., Atrazine Removal Using Adsorption and Electrochemical Regeneration. Water Res. 2004, 38, 3067-3074.

9. Broseus, R.; Vincent, S.; Aboulfadl, K.; Daneshvar, A.; Sauve, S.; Barbeau, B.; Prevost, M., Ozone Oxidation of Pharmaceuticals, Endocrine Disruptors and Pesticides During Drinking Water Treatment. Water Res. 2009, 43, 4707-4717.

10. Hua, W.; Bennett, E. R.; Letcher, R. J., Ozone Treatment and the Depletion of Detectable Pharmaceuticals and Atrazine Herbicide in Drinking Water Sourced from the Upper Detroit River, Ontario, Canada. Water Res. 2006, 40, 2259-2266.

11. Snyder, S. A.; Adham, S.; Redding, A. M.; Cannon, F. S.; DeCarolis, J.; Oppenheimer, J.; Wert, E. C.; Yoon, Y., Role of Membranes and Activated Carbon in the Removal of Endocrine Disruptors and Pharmaceuticals. Desalination 2007, 202, 156-181.

12. Sotelo, J. L.; Ovejero, G.; Rodríguez, A.; Álvarez, S.; Galán, J.; García, J., Competitive Adsorption Studies of Caffeine and Diclofenac Aqueous Solutions by Activated Carbon. Chem. Eng. J. 2014, 240, 443-453.

13. Westerhoff, P.; Yoon, Y.; Snyder, S.; Wert, E., Fate of Endocrine-Disruptor, Pharmaceutical, and Personal Care Product Chemicals during Simulated Drinking Water Treatment Processes. Environ. Sci. Technol. 2005, 39, 6649-6663.

14. Chingombe, P.; Saha, B.; Wakeman, R. J., Sorption of Atrazine on Conventional and Surface Modified Activated Carbons. J Colloid Interface Sci. 2006, 302, 408-416.

15. Sanchez-Martin, M. J.; Rodriguez-Cruz, M. S.; Andrades, M. S.; Sanchez-Camazano, M., Efficiency of Different Clay Minerals Modified with A Cationic Surfactant in the Adsorption of Pesticides: Influence of Clay Type and Pesticide Hydrophobicity. Appl. Clay Sci. 2006, 31, 216228.

16. Yan, X. M.; Shi, B. Y.; Lu, J. J.; Feng, C. H.; Wang, D. S.; Tang, H. X., Adsorption and Desorption of Atrazine on Carbon Nanotubes. J Colloid Interface Sci. 2008, 321, 30-38.

17. Chen, G.-C.; Shan, X.-Q.; Wang, Y.-S.; Pei, Z.-G.; Shen, X.-E.; Wen, B.; Owens, G., Effects of Copper, Lead, and Cadmium on the Sorption and Desorption of Atrazine onto and from Carbon Nanotubes. Environ. Sci. Technol. 2008, 42, 8297-8302. 
18. Tang, W.-W.; Zeng, G.-M.; Gong, J.-L.; Liu, Y.; Wang, X.-Y.; Liu, Y.-Y.; Liu, Z.-F.; Chen, L.; Zhang, X.-R.; Tu, D.-Z., Simultaneous Adsorption of Atrazine and Cu (II) from Wastewater by Magnetic Multi-Walled Carbon Nanotube. Chem. Eng. J. 2012, 42, 470-478.

19. Salvestrini, S.; Sagliano, P.; Iovino, P.; Capasso, S.; Colella, C., Atrazine Adsorption by Acid-Activated Zeolite-Rich Tuffs. Appl. Clay Sci. 2010, 49, 330-335.

20. Chaparadza, A.; Hossenlopp, J. M., Adsorption Kinetics, Isotherms and Thermodynamics of Atrazine Removal Using a Banana Peel Based Sorbent. Water Sci. Technol. 2012, 65, 940947.

21. Furukawa, H.; Cordova, K. E.; O'Keeffe, M.; Yaghi, O. M., The Chemistry and Applications of Metal-Organic Frameworks. Science 2013, 341, 1230444.

22. Maes, M.; Schouteden, S.; Alaerts, L.; Depla, D.; De Vos, D. E., Extracting Organic Contaminants from Water Using the Metal-Organic Framework CrIII(OH). $\{\mathrm{O} 2 \mathrm{C}-\mathrm{C} 6 \mathrm{H} 4-\mathrm{CO} 2\}$. Phys. Chem. Chem. Phys. 2011, 13, 5587-5589.

23. Jiang, J.-Q.; Ashekuzzaman, S. M., Development of Novel Inorganic Adsorbent for Water Treatment. Curr. Opin. Chem. Eng. 2012, 1, 191-199.

24. Van de Voorde, B.; Bueken, B.; Denayer, J.; De Vos, D., Adsorptive Separation on Metal-Organic Frameworks in the Liquid Phase. Chem. Soc. Rev. 2014, 43, 5766-5788.

25. Burtch, N. C.; Jasuja, H.; Walton, K. S., Water Stability and Adsorption in Metal-Organic Frameworks. Chem. Rev. 2014, 114, 10575-10612.

26. Dias, E. M.; Petit, C., Towards the Use Of Metal-Organic Frameworks for Water Reuse: A Review of the Recent Advances in the Field of Organic Pollutants Removal and Degradation and the Next Steps in the Field. J. Mater. Chem. A 2015, 3, 22484-22506.

27. Park, K. S.; Ni, Z.; Cote, A. P.; Choi, J. Y.; Huang, R.; Uribe-Romo, F. J.; Chae, H. K.; O'Keeffe, M.; Yaghi, O. M., Exceptional Chemical and Thermal Stability of Zeolitic Imidazolate Frameworks. Proc. Natl. Acad. Sci. U S A 2006, 103, 10186-10191.

28. Cavka, J. H.; Jakobsen, S.; Olsbye, U.; Guillou, N.; Lamberti, C.; Bordiga, S.; Lillerud, K.P., A New Zirconium Inorganic Building Brick Forming Metal Organic Frameworks with Exceptional Stability. J. Am. Chem. Soc. 2008, 130, 13850-13851.

29. Moreira, M. A.; Santos, J. C.; Ferreira, A. F.; Loureiro, J. M.; Ragon, F.; Horcajada, P.; Shim, K. E.; Hwang, Y. K.; Lee, U. H.; Chang, J. S.; Serre, C.; Rodrigues, A. E., Reverse Shape Selectivity in the Liquid-Phase Adsorption of Xylene Isomers in Zirconium Terephthalate MOF UiO-66. Langmuir 2012, 28, 5715-5723.

30. Bárcia, P. S.; Guimarães, D.; Mendes, P. A. P.; Silva, J. A. C.; Guillerm, V.; Chevreau, H.; Serre, C.; Rodrigues, A. E., Reverse Shape Selectivity in the Adsorption of Hexane and Xylene Isomers In MOF UiO-66. Microporous Mesoporous Mater. 2011, 139, 67-73.

31. Chavan, S.; Vitillo, J. G.; Gianolio, D.; Zavorotynska, O.; Civalleri, B.; Jakobsen, S.; Nilsen, M. H.; Valenzano, L.; Lamberti, C.; Lillerud, K. P.; Bordiga, S., $\mathrm{H}^{2}$ storage in isostructural UiO-67 and UiO-66 MOFs. Phys. Chem. Chem. Phys. 2012, 14, 1614-1626.

32. Streat, M.; Sweetland, L. A., Removal of Pesticides from Water Using Hypercrosslinked Polymer Phases. Process Saf. Environ. Prot. 1998, 76, 127-134.

33. Nam, S. W.; Choi, D. J.; Kim, S. K.; Her, N.; Zoh, K. D., Adsorption Characteristics of Selected Hydrophilic and Hydrophobic Micropollutants in Water Using Activated Carbon. J. Hazard. Mater. 2014, 270, 144-152.

34. Fu, Y. Y.; Yang, C. X.; Yan, X. P., Fabrication of ZIF-8@SiO2 Core-Shell Microspheres as the Stationary Phase For High-Performance Liquid Chromatography. Chemistry 2013, 19, 13484-13491. 
35. Katz, M. J.; Brown, Z. J.; Colon, Y. J.; Siu, P. W.; Scheidt, K. A.; Snurr, R. Q.; Hupp, J. T.; Farha, O. K., A Facile Synthesis of UiO-66, UiO-67 and Their Derivatives. Chem. Commun. 2013, 49, 9449-9451.

36. Audu, C. O.; Nguyen, H. G. T.; Chang, C.-Y.; Katz, M. J.; Mao, L.; Farha, O. K.; Hupp, J. T.; Nguyen, S. T., The Dual Capture of AsVand AsIIIby UiO-66 and Analogues. Chem. Sci. 2016, 7, 6492-6498.

37. Hasan, Z.; Jeon, J.; Jhung, S. H., Adsorptive Removal Of Naproxen and Clofibric Acid from Water Using Metal-Organic Frameworks. J. Hazard. Mater. 2012, 209-210, 151-157.

38. Freundlich, H., Over the Adsorption in Aolution. J. Phys. Chem. 1906, 57, 385-470.

39. Langmuir, I., The Constitution and Fundamental Properties of Solids and Liquids. Am. Chem. Soc. 1916, 38, 2221-2295.

40. Koble, R. A.; Corrigan, T. E., Adsorption Isothermsfor Pure Hydrocarbons. Ind. Eng. Chem. 1952, 44, 383-387.

41. Gao, Y.; Deshusses, M. A., Adsorption of clofibric acid and ketoprofen onto powdered activated carbon: Effect of natural organic matter. Environ. Technol. 2011, 32, 1719-1727.

42. Ho, Y. S.; McKay, G., A Comparison of Chemisorption Kinetic Models Applied to Pollutant Removal on Various Sorbents. Process Saf. Environ. Prot. 1998, 76, 332-340.

43. Ho, Y.S.; McKay, G., Pseudo-Second Order Model for Sorption Processes. Process Biochem. 1999, 34, 451-465.

44. Tarazona, P.; Marconi, U. M. B.; Evans, R., Phase Equilibria of Fluid Interfaces and Confined Fluids. Mol. Phys. 1987, 60, 573-595.

45. Lastoskie, C.; Gubbins, K. E.; Quirke, N., Pore size distribution analysis of microporous carbons: a density functional theory approach. J. Phys. Chem. 1993, 97, 4786-4796.

46. Ghosh, P.; Colon, Y. J.; Snurr, R. Q., Water Adsorption in Uio-66: The Importance of Defects. Chem. Commun. 2014, 50, 11329-11331.

47. Ebrahim, A. M.; Levasseur, B.; Bandosz, T. J., Interactions of $\mathrm{NO}_{2}$ With Zr-Based MOF: Effects of the Size of Organic Linkers on $\mathrm{NO}_{2}$ Adsorption At Ambient Conditions. Langmuir 2013, 29, 168-174.

48. Zhu, X.; Li, B.; Yang, J.; Li, Y.; Zhao, W.; Shi, J.; Gu, J., Effective Adsorption and Enhanced Removal of Organophosphorus Pesticides from Aqueous Solution By Zr-Based Mofs of UiO-67. ACS Appl. Mater. Interfaces 2015, 7, 223-231.

49. Han, S.; Liu, K.; Hu, L.; Teng, F.; Yu, P.; Zhu, Y., Superior Adsorption and Regenerable Dye Adsorbent Based on Flower-Like Molybdenum Disulfide Nanostructure. Sci. Rep. 2017, 7, 43599. 
Table of Contents Graphic

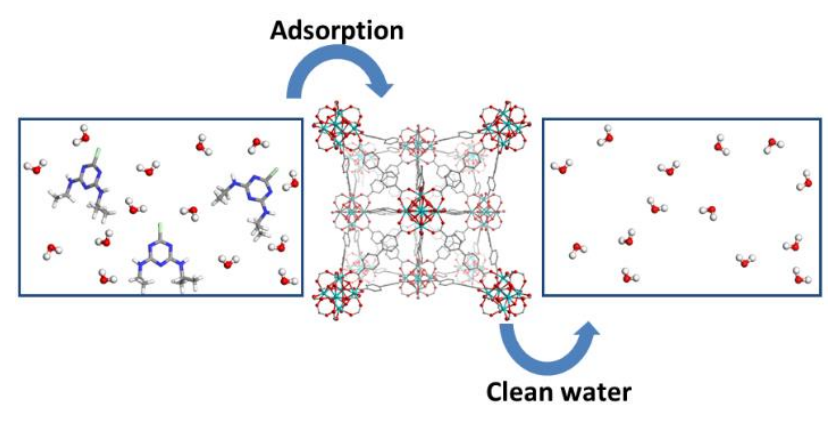

